\title{
Role of Linguistics Teachers in the Development of Socio-Communicative and Ethico- Sociability Skills among University Students of Southern Khyber Pakhtunkhwa
}

\author{
* Dr. Ghani Rahman, Assistant Professor \\ ** Dr. Syed Shujaat Ali, Chairman/Assistant Professor (Corresponding Author) \\ *** Mr. Tariq Amin, Visiting Lecturer
}

\begin{abstract}
Individuals' ethical sociability and communicational skills enjoy core importance in their societal and organizational functioning. Generally, a fear is felt regarding the students doing MA English, at the universities of Pakhtunkhwa province; the fear is that the students who do MA English leads to weakening of their practice of their socio-cultural values. This apprehension was looked into by analyzing the role that particular, the teachers of Linguistics can play in the transmission, preservation, and promotion of their socio-cultural values; the teachers can help the learners develop an understanding of sociability skills and appropriate socio-communicative skills. The socio-cultural sphere was delimited to the aspects of ethico-sociability and socio-communicative skills. Three public sector universities, namely Gomal University, Kohat University, and Bannu University, from south Khyber Pakhtunkhwa province served as the universe of the study. Students studying at master's Level in their Departments of English, served as research population, for evaluating the teachers' role, in the promotion of ethico-sociability and socio-communicative skills. The data was collected through the interview method. Results show that most of the teachers of Linguistics promote the learners' understanding of social etiquette, social norms, and expectations of politeness, appropriacy, communicative competence, cultural transmission, effective communication, and sociability skills.
\end{abstract}

Keywords: Ethico-Sociability, Socio-communicational Skills, Communicative Competence, Appropriateness, and Morality

\section{Introduction}

Due to easy and frequent exposure to lifestyles and manners of some secular, amoral and perverted foreign cultures through media, the local culture is under the consistently increasing risk of crumbling down. The flooding of local markets with cheap and handy gadgets like mobiles, laptops, I-phones, and tablets has added to the intensity of the problem manifold. The highly valued culture of face-toface interaction in immediate surroundings, mutuality, sharing, sociability, social communication, informal socializing through local social institutes like Hujra (a collective and public guest housecum-sitting room of male members belonging to a group of houses) is being rapidly replaced by a culture of individualism and privacy, where everyone is free to switch over to any channel, website, and social group without any elder's supervision over the youngsters; the social pressure by the elders of the society over the youngsters, with a focus on maintaining moral and socially acceptable behavior, is diminishing fast.

Significant levels of moral deprivation and lack of inculcation of sociability and ethical values are felt among the younger generation. Because of this, they feel less satisfied and less successful human beings with a great deal of psychological problems. Society seems disintegrating but what seems more disturbing to the masses is that educational institutes which were considered places for socializing individuals and elevating their morality are, according to them, also falling short of their targets. The curricula of some courses, like English or science, taught at the university level are also

\footnotetext{
* Department of English, Hazara University, Mansehra. Pakistan. Email: ghani_saba@yahoo.com

** Department of English, Kohat University of Science \& Technology, Kohat.

Email: s_shojaat_ali@yahoo.com

*** Department of English, Kohat University of Science \& Technology, Kohat.

Email: tariq.ktk.733@gmail.com
} 
considered to be, day by day, becoming devoid of inculcating social values and high standards of morality and social communication.

The subject of English for its development of an opposite worldview among students is targeted in specific, for divesting learners of their cultural values. These facts have justified the writing of this paper, under which, the researcher wants to find out whether the teaching of a course of scientific nature like Linguistics from the curriculum of MA English, which belongs both to the discipline of English and science at the same time, can lead to the development of good sociocommunicative and ethico-sociability skills, in its learners. This research has explored the important issues of learners' sociability skills promotion to their teacher's input.

\section{Objectives of the Study}

1. To ascertain the transfer and maintenance of our cultural values through the university degree program of MA English, especially in the subject of Linguistics.

2. To dispel the fear and concern of the students' parents about the social utility of the MA English degree program taught inside universities.

3. To highlight the role of Linguistics teacher in the social training of his/her students.

4. To re-evaluate and re-formulate our educational policy along modern lines by the findings of the study.

\section{Hypotheses of the Study}

Research Hypothesis-1. "The teachers of Linguistics play a very significant role in ethico-sociability and promotion of socio-communicational skills among learners of Linguistics from public sector universities belonging to the study region".

Alternative Research Hypothesis-2. "The teachers of Linguistics play an insignificant role in ethicosociability and promotion of socio-communicational skills among learners of Linguistics from public sector universities belonging to the study region".

\section{Literature Review}

Culture leads to the acquisition of language and language guides towards the formation of social reality. Humans are born with an ability to acquire language but not with the ability to produce utterances automatically in a language. They acquire their first language as children inside a culture in which the cultural transmission process of a language takes place (Smith, 2003; Yule, 2010). According to George Yule (2010), in the human acquisition process, cultural transmission is indispensable for acquiring a particular language whereas on the other hand, according to Halliday (1978), an important basic function of language is to help construct social reality. Language, according to him, has a system of meaning, capable enough to transmit cultural values (ibid). Along with learning the language of a culture, a child, at the same time, is learning those meanings that are associated with that culture, with the help of the lexico-grammatical system of that language (Ibid).

Each language results in a specific worldview. However, when certain languages get mixed due to code-mixing and code-switching, no language can maintain the culture and morality underpinning it, with perfection. Due to unlimited exposure to communication technology and media, one cannot maintain the purity of one's language and as a result, too much code-switching and codemixing take place (Al-Mulheim, n.d.; Cárdenas-Claros \& Isharyanti, 2009; Ehsan \&Aziz, 2014). This results in a replacement of original words with foreign words and consequently in an inability to uphold its values in entirety and express a single idea purely in mother-tongue, without using words from other codes.

Communicative competence, according to Yule (2010), does not imply the use of language in an accurate manner only, in which the emphasis is on grammatical correctness; rather it implies the use of language with appropriacy and flexibility, besides the quality of accuracy. We adopt different behaviors and languages, in different circumstances based on different factors like roles and relationships of participants, topics, and setting of conversation. The ability to use language appropriately in a social context is called sociolinguistic competence (Yule, 2002). Students are taught in the values and norms of their culture, for making them better sociable citizens of the society and they are corrected and guided by their teachers about e.g. which language to use informal environments like school and which one to use with one's close friends or siblings at home. The ability to organize messages effectively and flexibly for overcoming potential problems of communication in interaction is called strategic competence. It guides a speaker which strategies to 
employ when the speaker misses or is lacking in exact and proper words for expressing an idea or when there is a gap between what is intended and what is available for expressing that intended content.

Instead of using language for exchanging ideas only, it can also be used to perform, directly or indirectly, different speech acts of requesting, suggesting, ordering, promising, and inquiring. For the sake of civility, politeness, and courtesy in interaction, sometimes, a person would be using a sentence which, on the face of it, would appear to be a question, but would be an indirect speech act, functioning indirectly for making a polite request or suggestion.

As a positive gesture and a sign of good and polished behavior, a speaker normally utters polite expressions that create a good impression on the listener. In a healthy society, a relation of amicability does not endorse a person's asking or calling another person of equal status authoritatively, to do something; one may ask another to help, but with the addressee's self-respect and no harm to his/her ego and public self-image. In pragmatics, the face of a person means his/her self-image and politeness are to show awareness of and have consideration for another person's face (Fridaanjani, 2015; Markus, 2011). Linguistically speaking, a speaker shows a positive face, when he/she uses expressions that befriend and bring the listener closer, in contrast to showing a negative face by using expressions that domineer the listener and impose authority over the listener. Telling someone directly to do something implies that the speaker has more social power than the address. However, in case of absence of social power, an act of telling someone to do something is a facethreatening act which can be made a face-saving act through the use of a polite indirect speech act in question form (cf. Markus, 2011; Rash, 2004). Even without using polite and courteous words, a speaker can bring the other participant of conversation closer through linguistic convergence, whereby the speech style of the other participant of conversation is adopted; this brings both the participants closer and more intimate. On the contrary, adopting a style different from that of the other participant causes alienation and leads to the creation of social distance between the participants.

Difference of sociolects or regional dialects often serves as a source of mocking and contempt among speakers of different dialects (Braier, 2013; Ingram, 2009). A student, for having a difference in vocabulary and pronunciation, needs not to be made the laughingstock, among most students speaking the same dialect or sociolect. It is a natural social phenomenon that, within the same geographical area, different social classes speak language differently and, in a bit, different geographical area, speakers normally have differences in accent, pronunciation, and vocabulary. Speakers of social groups differing in economic status and education indicate their membership of a specific speech community, the individuals of which share a set of expectations and norms, in connection with the use of language.

According to the norms of conversation, each participant talks in turns, and it is considered very awkward on the part of the speaker if he/she interpolates in the conversation at the improper point or cuts in on another participant's speech before he/she has completed his/her turn (Carrol, 2011; Dubois et al., 1996; Raux \& Eskenazi, 2009). Conversation carries forward by the tacit mutual agreement on the principle of cooperation, between the parties (Davies, 2000; Grice, 1975; Zhou, 2009). Cooperative principle, according to Paul Grice (1975) comprises of four maxims, namely the quantity maxim, according to which the contributed information should neither be less nor more than is required, the relation maxim, according to which the information shared should be relevant, and the manner maxim, according to which, the information shared should be orderly, clear and brief, and the quality maxim, according to which, no such information should be shared that is unconfirmed or without sufficient evidence. If the speaker is not sure about the accuracy or veracity of the content, then he/she may use a defensive facade of expressing things in less definitive terms called hedges (Jakobsson, 2010; Neary-Sundquist, 2013), leaving space for rejection or correction by another participant.

Human beings differ in their opinions, which ultimately leads to perfection. However, this difference can lead to a great deal of opposition and rift in the society, if not handled properly. One may disagree with another, but the expression of disagreement used, must not be blunt and rude (cf. Edstrom, 2004; Pomerantz \& Heritage, 2012); instead, it should be phrased in such a way that the opposition is hinted at indirectly, politely, and does not hurt the feelings of another party. 
In the preservation of national heritage and language, teachers of linguistics play a crucial role. By teaching the importance of national language, they motivate students to learn the national language. They are enabled to communicate in the national language to make them work and interact with all the citizens of the nation. Similarly, keeping various national and cultural considerations in view, governments employ linguists in making decisions regarding the selection, promotion, and then development of national language and official language, among the different languages spoken inside a country; they chose and then promoted a dialect as a standard one (Smoke, 2012), for education, among the various geographical and social dialects of a region, and they chose a language as the medium of instruction for each stage of education. Linguistically, no dialect or language can be considered inherently deficient, in the sense that it will have means to express all those things that other languages can express. As compared to the vernacular or crude kind of dialect spoken by lowerstatus groups, some dialects or languages assume higher social status and are seen in a more positive light, due to their use by an important group of the society or due to their connection to a cultural or political center.

Besides getting information etc., language, according to phatic communication, is also used to get closer to other individuals of the society and to put an end to strangeness and silence (DeVito, 2002; Gomez, 2000; Freeman et al. 2005). Due to this, we discuss topics that are popular or universal like weather conditions, etc that are too obvious to be unknown, yet we do it to break the ice and to come closer to other people. Psychologically everybody wants recognition and one of the effective ways to give them their due share of recognition is to address them with their proper full names or by the names they want themselves to be called with.

According to Yule (2002), the speech style of a speaker can be either careful, called formal speech style or casual called, informal speech style (cf. Selting, 1989). Students coming from the family environment are prone to use informal code of language, the use of which seems awkward inside the formal environment of school. Certain collocations or expressions are appropriate for certain contexts, depending upon status or social distance between speaker and hearer (Akerlof, 1997; Biel, 2007; Pham, 2013). It is accepted that choosing our words carefully in certain situations is more important than choosing grammatical structures (Harmer 1991). In a language of a given culture, because of repeated cooccurrence in popular literary works or because of their being used together traditionally for a long time, some words get so much associated that afterward they are inclined to appear together. We use particular words or phrases quite frequently and some of them are more common than others. Using another synonymous word in place of the usual word from that pair would be grammatically correct but would not be accepted as correct because of its being not in usual practice. Research provides more evidence in favor of it, that our understanding of what words and phrases mean, is tied to the contexts in which they are typically used (Yule, 2002).

\section{Methodology}

The nature of the study is descriptive, stating the prevailing condition of ethico-sociability and sociocommunicative skills promotion by teachers of Linguistics, among university-level learners. This section provides information about the sampling technique, the universe, data collection, and analyses and discussion of the study, respectively.

\section{Population of the Study}

Public sector universities of the southern region of the province of Khyber Pakhtunkhwa served as the universe of the study, and students at Masters level, in the Departments of English, at Kohat University of Science and Technology, Kohat (KUST) and Gomal University, Dera Ismail Khan served as research population, for evaluating the teachers' role, in the promotion of ethico-sociability and socio-communicational skills. In this study, a sample size of 40 respondents was selected, which comprised the male \& female learners in the Departments of English, from Kohat University of Science and Technology, Kohat and Gomal University, Dera Ismail Khan.

\section{Sampling and Sampling procedure}

In this study, the nature of respondents was male and female master's level students in the Department of English, at Kohat University of Science and Technology, Kohat and Department of English, at Gomal University, Dera Ismail Khan. Census method was adopted. In southern Khyber Pakhtunkhwa. There are four public sector universities where the subject of Linguistics is taught at the master's level. English departments from the Kohat University of Science and Technology, Kohat and Gomal 
University, Dera Ismail Khan were selected for the research. In this study, a sample size of 40 respondents from the final year was selected, which comprised the male and female learners in the departments of English from the above mentioned two universities.

\section{Method of Data Collection}

The interview schedule was used, by incorporating a Lickert scale, as a tool for data collection purposes. Closed-ended questions were constructed for the formulation of the interview schedule. After conducting the interviews, the data was classified and tabulated; the frequencies and the percentages were drawn accordingly. The tabulated data was described in a textual meaningful form.

\section{Analysis and Discussion}

This section deals with the quantitative data analysis of the primary data collected through interviews of the respondents and resulting discussion over it. Out of the total 40(100\%) respondents, $18(45 \%)$ were female respondents, while 22(55\%) were male respondents. All the respondents were almost from the same age group of 22-23 years.

In variable-1, the data shows the role of the teacher of Linguistics in increasing students' understanding of their culture by elaborating socio-communicative phenomena of the subject regarding their own culture. 20(50\%) respondents say that the teacher does it always, $13(32.5 \%)$ respondents say that the teacher does it most often, $7(17.5 \%)$ respondents say that the teacher does it but rarely and $0(0 \%)$ respondents say that the teacher never does it. Teachers impart knowledge about mechanisms of learners' culture, in addition to teaching the technical aspects of Linguistics. Students are taught that culture is so important that language cannot be acquired without a culture, automatically, like the songs of birds. Culture and language are so interconnected that feeling ashamed of or avoiding using one's language is like disowning one's culture.

In variable 2, the data shows the role of the teacher of Linguistics in warning students against too much code-mixing and code-switching. 13(32.5\%) respondents say that the teacher does it always, $13(32.5 \%)$ respondents say that the teacher does it most often, $8(20 \%)$ respondents say that the teacher does it rarely and 6(15\%) respondents say that the teacher never does it. The students get guidance, regarding the maintenance of purity in the use of their mother tongue. Their mother tongue is laden with their culture and if they want to retain their culture, then they would abstain from mixing it with different languages unless required indispensably.

In variable 3, the data shows the role of the teacher of Linguistics in emphasizing the maintenance of good social relations by learning sociability and communicative competence. $12(30 \%)$ respondents say that the teacher does it always, 14(35\%) respondents say that the teacher does it most often, $6(15 \%)$ respondents say that the teacher does it but rarely and $8(20 \%)$ respondents say that the teacher never does it. For civility, decorum, and courtesy in interaction, students are trained for the three constituent competencies of communicative competence.

In variable-4, the data shows the role of the teacher of Linguistics in guiding why and how to talk politely and why in case of absence of social power, telling someone to do something is a facethreatening act. 12(30\%) respondents say that the teacher does it always, 23(57.5\%) respondents say that the teacher does it most often, $3(7.5 \%)$ respondents say that the teacher does it but rarely and $2(5 \%)$ respondents say that the teacher never does it. A significant majority of students say that teachers guide them about the use of polite expressions as everybody has a public self-image which is too sacrosanct for him/her, to be harmed by impolite expressions, called face-threatening acts. It is taught to them that except in teacher-student, parent-child, and boss-subordinate relationships; one should not directly ask someone to do something for one. As humans are not self-sufficient and need one another constantly in society, therefore, for making others to do something for one, one should ask them through indirect speech acts, in the form of polite questions, suggestions etc.

In variable 5, the data shows the role of the teacher of Linguistics in guiding the students for communicating in the speech style of the other participant of conversation. 15(37.5\%) respondents say that the teacher does it always, 15(37.5\%) respondents say that the teacher does it most often, $7(17.5 \%)$ respondents say that the teacher does it but rarely and 3(7.5\%) respondents say that the teacher never does it. Students are guided in the ways of facilitating communication with other participants of conversation and in removing alienation with them, by adopting their speech style.

In variable 6, the data shows the role of the teacher of Linguistics in explaining to the students, the importance of speech acts and in imparting them training regarding the correct use of 
them. 13(32.5\%) respondents say that the teacher does it always, 17(42.5\%) respondents say that the teacher does it most often, $8(20 \%)$ respondents say that the teacher does it but rarely and $2(5 \%)$ respondents say that the teacher never does it. To teach students about the desirable manners of conversation and interaction, they are guided about the identification of different indirect speech acts and their function, appropriate use, and intended meaning in different contexts.

In variable 7 , the data shows the role of the teacher of Linguistics in guiding students regarding etiquette and cooperative principles of conversation (cf. Carrol, 2011; Grice, 1975; Markus, 2011; Raux \& Eskenazi, 2009). 12(30\%) respondents say that the teacher does it always, 16(40\%) respondents say that the teacher does it most often, $7(17.5 \%)$ respondents say that the teacher does it but rarely and 5(12.5\%) respondents say that the teacher never does it. The students are guided about the proper way of slipping into the conversation by identifying to them the appropriate points of participation and about giving others a good listening without interrupting them when they are speaking. They are taught that the participants should also be such that it follows the three maxims of quality, quality, and order. When these principles and etiquettes are not observed by one party of the conversation, then it will cause displeasure and irritation to the other party, leading to failure in conversation and thereby to the communication gap.

In variable-8, the data shows the role of the teacher of Linguistics in explaining the rationale for using hedges and imparting training regarding their use (cf. Jakobsson, 2010; Neary-Sundquist, 2013). 6(15\%) respondents say that the teacher does it always, 20(50\%) respondents say that the teacher does it most often, $12(30 \%)$ respondents say that the teacher does it but rarely and $2(5 \%)$ respondents say that the teacher never does it. Students are discouraged to make sweeping statements and to claim something vigorously without sufficient evidence and conviction. In cases of uncertainty and less evidence, they are guided to maintain their credibility and keep themselves on the safer side by relying on hedges.

In variable 9, the data shows the role of the teacher of Linguistics in teaching students regarding politely disagreeing with others (cf. Edstrom, 2004; Pomerantz \& Heritage, 2012). 10(25\%) respondents say that the teacher does it always, 14 (35\%) respondents say that the teacher does it most often, $10(25 \%)$ respondents say that the teacher does it but rarely and $4(10 \%)$ respondents say that the teacher never does it. As social beings, we interact with one another, and internal differences do arise, which is a positive sign of a progressive society. However, disagreement can be communicated without hurting others' feelings and without distancing others. The data shows that students get training in respect of disagreeing with others in a palatable and polite manner instead of a blunt and disparaging manner.

In variable-10, the data shows the role of the teacher of Linguistics in explaining appearance as a powerful non-verbal communication. 13(32.5\%) respondents say that the teacher does it always, $16(40 \%)$ respondents say that the teacher does it most often, $9(22.5 \%)$ respondents say that the teacher does it but rarely and 2(5\%) respondents say that the teacher never does it. Students get the lesson of keeping themselves neat, clean, and disciplined in attitude, dress, and lifestyle to make a wholesome effect on the society around them.

In variable-11, the data shows the role of the teacher of Linguistics in teaching respect for all dialects and sociolects along with their speakers. 18(45\%) respondents say that the teacher does it always, $18(45 \%)$ respondents say that the teacher does it most often, $4(10 \%)$ respondents say that the teacher does it but rarely and $0(0 \%)$ respondents say that the teacher never does it. Teachers guide that a specific dialect or sociolect should neither be laughed at nor held in contempt as all of them are inherently equal from a linguistics point of view. They are made to realize that variations in language, social classes, and sub-cultures are natural and their respective language and habits also seem queer to other people who speak separate dialects or sociolects. They are guided to get rid of their irrational biases and discriminative attitude towards one another's classes, sociolects, and dialects which leads them to live in harmony with one another in society.

In variable-12, the data shows the role of the teacher of Linguistics in explaining and insisting on the use of national and official languages. 23(57.5\%) respondents say that the teacher does it always, $8(20 \%)$ respondents say that the teacher does it most often, $7(17.5 \%)$ respondents say that the teacher does it but rarely and $2(5 \%)$ respondents say that the teacher never does it. If some dialect or language is chosen as standard or as a medium of instruction, it does not imply that it was better than 
others. Choosing languages as national, official, and as a medium of instruction is done by keeping various national, cultural, and educational considerations in the better interests of the whole nation, and then policies for their enrichment and implementation are framed. Students, being representatives of the cultured class and the educated class, are guided and encouraged towards the learning and use of national and official languages to communicate and interact with all the citizens on the national level and to be looked up to, inside their society.

In variable-13, the data shows the role of the teacher of Linguistics in explaining the negative implication of silence and the rationale for avoiding it. 7(17.5\%) respondents say that the teacher does it always, 19(47.5\%) respondents say that the teacher does it most often, 11(27.5\%) respondents say that the teacher does it but rarely and 3(7.5\%) respondents say that the teacher never does it. Students are taught that if we do not use language unless we feel the need of using it for some material purpose, then we run the risk of alienating other members of society.

In variable-14, the data shows the role of the teacher of Linguistics in encouraging students to address others with good names. 9(22.5\%) respondents say that the teacher does it always, 19 (47.5\%) respondents say that the teacher does it most often, 7 (17.5\%) respondents say that the teacher does it but rarely and $4(10 \%)$ respondents say that the teacher never does it. As psychologically everybody wants recognition and respect, therefore, students are correctly guided by calling others with names that are full, correct, and liked by them, and not with funny ones.

In variable-15, the data shows the role of the teacher of Linguistics in developing skills of sociability in students. $12(30 \%)$ respondents say that the teacher does it always, $14(35 \%)$ respondents say that the teacher does it most often, 12(30\%) respondents say that the teacher does it but rarely and $25 \%)$ respondents say that the teacher never does it. Most students of linguistics get guidance regarding the social importance of greeting others and are taught sociability skills like addressing elders and teachers with a suitable social dialect that shows respect for them.

In variable-16, the data shows the role of the teacher of Linguistics in warning against using informal language instead of formal, informal situations. $11(27.5 \%)$ respondents say that the teacher does it always, 21(52.5\%) respondents say that the teacher does it most often, 6(15\%) respondents say that the teacher does it but rarely and $2(5 \%)$ respondents say that the teacher never does it. Students coming from the family environment are prone to use the informal code of language. The teachers teach them regarding the different environments, suitable for the use of formal and informal codes respectively, to be socially acceptable.

In variable-17, the data shows the role of the teacher of Linguistics in teaching about collocation. 11(27.5\%) respondents say that the teacher does it always, 15(37.5\%) respondents say that the teacher does it most often, $8(20 \%)$ respondents say that the teacher does it but rarely and $6(15 \%)$ respondents say that the teacher never does it. Students are taught that certain words go in pairs and replacing a word from the pair with another synonym is traditionally incorrect and unacceptable.

\section{Conclusion}

The findings of paper make it clear that the role of teachers of Linguistics is very much instrumental in the inculcation of ethical and moral values in the university learners and in making them good and productive citizens of the society. They play a great job of socializing students at universities inside southern Pakhtunkhwa, in addition to imparting the knowledge of subject that is technical. Due to the development of ethico-communicative and sociability skills, the learners come to know how to live in harmony with others inside the society, how to promote love and respect inside it, and how to avoid ruffling the feelings of one another. They are made sensitive to the realization of the proper manner of talking and the proper occasion of talking with the different members belonging to different strata of the society, thereby turning them into well-adjusted and cultured members of the society. The ensuing society is based on such type of interaction among its members which is free from ill-will and offense.

Analysis of the data leads to the conclusion that the hypothesis-1, "The teachers of Linguistics play very significant role in ethico-sociability and promotion of socio-communicational skills among learners of Linguistics from public sector universities belonging to the study region", stands true, while Research Hypothesis-2 i.e. "The teachers of Linguistics play an insignificant role in ethicosociability and promotion of socio-communicational skills among learners of Linguistics from public sector universities belonging to the study region", stands refuted. 
It is suggested that to elaborate socio-communicative and ethico-social phenomena, the teachers of Linguistics should try to do it through examples from the local culture of the learners, so that the socio-cultural understanding of the learners can be promoted concerning their own culture and they can be made well-adjusted members of their society and culture. In addition to teaching the technicalities of the subject, the teachers of Linguistics should take care of the social grooming of their students and the well-being of every one of the societies. Socializing the individuals of society and arming them with high moral values and etiquette of social life, the teachers of linguistics can turn the university graduates, having Masters in English, into highly productive members of their society and nation.

\section{References}

Al-Mulhim, N. (n.d.).The influence of media in encouraging code-mixing in Saudi Arabia. Final Project for Sociolinguistics Master Course. http://www.academia.edu/1016123/The_ Influence_of_Media_on_Encouraging_Code_Mixing_in_Saudi_Arabia

Akerlof, G. (1997). Social distance and social decisions. Econometrical, Vol. 65, No. 5 pp. 1005-1027

Biel, L. (2007). Communicative distance in interaction: verbal and nonverbal expression in English. Rzeszow: Wydawnictwo Uniwersytetu Rzeszowskiego, 175-183.

Braier, R. (2013). Jafaican it? No, we are not. The Guardian. $30^{\text {th }}$ of August 2013. http://www.theguardian.com/media/mind-your-language/2013/aug/30/mind-your-languagejafaican

Cárdenas-Claros, M. \& Isharyanti, N. (2009). Code-switching and code-mixing in Internet chatting: between 'yes', 'ya', and 'si' a case study. Jaltcalljournal. Vol. 5, No. 3 Pages 67-78. http://journal.jaltcall.org/articles/5_3_Cardenas.pdf

Carrol, D. (2011). Taking Turns and Talking Naturally: Teaching Conversational Turn-Taking. In Houck, N. \& Tatsuki, D. (Eds.), Pragmatics: Teaching Natural Conversation. Alexandria, VA: Teachers of English to Speakers of Other Languages, Inc.

Davies, B. (2000). Grice's cooperative principle: getting the meaning across. Nelson, D. \& P. Foulkes (eds.), Leeds Working Papers in Linguistics. 8 (2000), pp. 1-26. file:///C:/Users/waqas_000/ Downloads/Davies2000.pdf

DeVito, J. (2002). Human communication. A sample chapter was published by Pearson. http://catalogue.pearsoned.co.uk/samplechapter/0205353908.pdf

Dubois, S., Boutin, M., Sankoff, D. (1996). The quantitative analysis of turn-taking

In multiparticipant conversations. UPenn Working Papers in Linguistics, Volume 3, 1 (1996).

Ehsan, A. \&Aziz, S. (2014). Code-mixing in Urdu news of a private Pakistani channel: a case study. Academic Research International. 44 Vol. 5 No. 1.

Estdrom, A. (2004). Expressions of disagreement by Venezuelans in conversation: reconsidering the influence of culture. Journal of Pragmatics. Volume 36, Issue 8, pp. 1499-1518

Freeman, Y., Freeman, D., \& Mercuri, S. (2005). Dual language essentials for teachers and administrators. Portsmouth, NH: Heinemann.

Fridaanjani (2015). It is More Polite to Make a Request and Refuse It by Using Indirect Speech Acts. https://fridaanjani.wordpress.com/2015/07/04/its-more-polite-to-make-a-request-and-refuseit-by-using-indirect-speech-acts/

Geis, M. L. (2006). Speech acts and conversational interaction. Cambridge University Press.

George Psathas (Ed.). (1995). Conversation analysis: The study of talk-in-interaction (Vol. 35). Sage.

Gomez, L. (2000). Two-way bilingual education: Promoting educational and social change. The Journal of the Texas Association for Bilingual Education, 5(1), 43? 54.

Grice, H.P. (1975). Logic and conversation. In Cole, P. \& Morgan, J. (eds.) Syntax and Semantics, Volume 3. New York: Academic Press. pp. 41-58.

Hutchby, I., \& Wooffitt, R. (2008). Conversation analysis. Polity.

Ingram, P. (2009). Are accents one of the last acceptable areas for discrimination? Journal of Extension, 47(1). http://www.joe.org/joe/2009february/comm1.php

Jakobsson, S. (2010). A study of female language features in same-sex conversation. Student Thesis retrieved from http://www.diva-portal.org/smash/get/diva2:375135/fulltext01.pdf

Kaplan, R. B., \& Baldauf, R. B. (1997). Language planning from practice to theory (Vol. 108). Multilingual Matters. 
Kramsch, C. J. (1998). Language and culture (Vol. 3). Oxford: Oxford University Press.

Markus, M. (2011). Politeness in Interaction - An analysis of politeness strategies in online learning and teaching. Student Thesis. http://www.diva-portal.org/smash/get/diva2:447675/FULL TEXT01.pdf

Neary-Sundquist, C. (2013). THE use of hedges in the speech of ESL learners. ELIA 13, pp. 149-174

Pham, T. (2013). The influence of social distance on expressions of gratitude in Vietnamese. The Internet Journal Language, Culture, and Society. www.aaref.com.au/attachment. aspx?id=2266

Pomerantz, A. \& Heritage, J. (2012). Preference. In Sidnell, J. \& Stivers, T. (Eds.), the Handbook of Conversation Analysis. Wiley-Blackwell. Pp. (210-228)

Rash, F. (2004). Linguistic politeness and greeting rituals in German-speaking Switzerland. Linguistik online 20,3/04. http://www.linguistik-online.com/20_04/rash.html

Raux, A. \& Eskenazi, M. (2009). A Finite-State Turn-Taking Model for Spoken Dialog Systems. Human Language Technologies: The 2009 Annual Conference of the North American Chapter of the ACL, pages 629-637. http://www.aclweb.org/anthology/N09-1071

Scarcella, R. C., Andersen, E. S., \& Krashen, S. D. (Eds.). (1990). Developing communicative competence in a second language. Heinle \& Heinle.

Selting, M. (1989). Speech style in conservation as an interactive achievement. Institutional Repository of the Potsdam University: In: Postprints der Universitat Potsdam https://publishup.uni-potsdam.de/opus4-ubp/files/4110/speech.pdf

Sinclair, J. (1991). Corpus, concordance, collocation (Vol. 1). Oxford: Oxford University Press.

Smith, K. (2003). The Transmission of Language: models of biological and cultural evolution. Ph.D. thesis. University of Edinburgh. Retrieved from: http://www.lel.ed.ac.uk/ simon/ dissertations/ksmith_thesis.pdf

Smoke, T. (2012). Language and its acquisition. In Luria, H.; Seymour, D.; Smoke, T. (Eds.), Language and Linguistics in Context: Readings and Applications for Teachers. Lawrence Erlbaum Associate, New Jersey.

Talbot, M. M., Atkinson, K., \& Atkinson, D. (2003). Language and power in the modern world. Edinburgh University Press.

Tannen, D. (2005). Conversational style: Analyzing talk among friends. Oxford University Press.

Watts, R. J. (2003). Politeness. Cambridge University Press.

Yule, G. (2010). The study of language, 4th Ed, Cambridge University Press.

Zhou, M. (2009). Cooperative Principle in oral English teaching. International Education Studies, Vol. 2 (3). 